\title{
POLLEN SPECTRUM AND PHENOLOGY OF STINGLESS BEE (Tetragonula biroi Friese) PLANTS
}

\author{
Marilyn B. Balderas \\ Faculty, College of Agriculture and Natural Resources, Central Bicol State University of Agriculture, 4418 San \\ Jose, Pili, Camarines Sur, Philippines
}

\begin{abstract}
The study was conducted to determine the pollen sources and bloom pattern of Tetragonula biroi Friese plants in Camarines Sur, Philippines. Floral resources within the 300-meter phenology transect were identified. EstimateS software was used for the analysis of rarefaction and pollen richness. A total of 111 plant species were suitable for meliponiculture in the lowland ecosystem and only 42 species in the upland ecosystem. Among the bee plants, 53\% non-seasonal, 35\% seasonal and $15 \%$ with intermittent flowering. Cocos nucifera was the major pollen sources with $19-73 \%$ occurrence in the samples. Pollens of Ceiba pentandra , Mangifera indica, Elaeis guineensis, Pterocarpus indicus, Syzygium spp., Persia americana, Areca catechu, Muntingia calabura, and Citrus spp. were dominant to secondary pollen sources, while the rest were minor pollen sources. Pollen spectrum showed a linear relationship with the bloom pattern. Interpolation with pollen spectrum and flowering plants plotted against time showed that both pollen diversity and abundance of blooming plants increased during the 12-month study period in the lowland ecosystem. No significant relationship was noted between the diversity of the foraged pollen and the bloom pattern. Rarefaction curve and pollen richness were higher in May than the rest of the months.
\end{abstract}

Keywords: bloom pattern, pollen, stingless bee, Tetragonula biroi

\section{INTRODUCTION}

The rich and diverse floral resources, warm and favorable climate of the Bicol Region are essential elements for beekeeping. The region is geographically located at the southeastern end of Luzon archipelago, Philippines, with a total land area of roughly $17,632.5 \mathrm{sq} \mathrm{km}$. Bicol region's $50 \%$ land area is agricultural, 30\% grassland, 13\% forestland, and the remaining are devoted to miscellaneous uses. The Philippine flora is at least 13,500 species and on the botanical survey conducted by Haribon Foundation in 1991, 1300 species of plants are recorded in Mt. Isarog alone.

Beekeeping in the region started in the hunting of wild bees Apisdorsata, Apiscerana and Tetragonula (Trigona)biroi, all are native bees in Bicol. Local beekeepers cultured native bees for honey and pollen production, and crop pollination. The culture of Apis mellifera and A. cerana in hive boxes were adopted later by some beekeepers in the provinces of Albay and Camarines Sur ( Mostoles et al., 2006; PCAFNRRD, 2007).

For the past decade, Tetragonula biroi Friese captured the interest of local beekeepers and recognized the potential of this species in beekeeping. The Regional Apiculture Center-Bicol (RAC-Bicol) at the Central Bicol State University of Agriculture introduced T. biroi and studied the culture of the bees. The technology of keeping T. biroi was then established and disseminated through the conduct of local training, national symposia, and conventions. The cultural management practices and the technology of raising the stingless bees are cheaper

Corresponding Author: marilyn.balderas@ cbsua.edu.ph 
and very simple than other bee species (Ruiz et al., 2003; Mostoles and Ruiz, 2004).

Feral colonies of stingless bees are abundant in the region and many beekeepers are encouraged to culture the stingless bees because they are freely hunted from the forest, they do not get stings, hive manipulation is easily learned, and the bees also produced honey, pollen, and propolis. Honey from $T$. biroi has been claimed by several beekeepers in the region to be an effective cure for asthma and other respiratory illness.

Stingless bees are generally polylectic and forage on a variety of plants that provide some pollen and nectar. Some bee species are known to use floral resources from more than a hundred taxa over a course of several seasons in a given habitat (Wilms, et al., 1996). The important aspect considered in beekeeping is the ample sources of nectar and pollen. Pollen is the protein-rich food, vital in the development of the brood to maintain colony strength and reproduction while nectar provides the energy for flight, foraging, and other hive activity (Grogan and Hunt, 1979; Roubik, 1989; Kevan, 1995; Buchmann and Nabhan, 1996). Identification of plants visited by stingless bees for pollen and nectar and their bloom pattern is useful in the selection of sites suited for meliponiculture in the region.

Therefore, the main objectives of this study were (1) to identify the pollen sources of stingless bees in Camarines Sur, (2) determine the spectrum of the pollen types and their value to $T$. biroi, and, (3) determine the relationship between the diversity of foraged pollens and the phenology of stingless bee plants. The outcome of this study is useful in the promotion, establishment and development of meliponiculture as a sustainable beekeeping industry in the Bicol Region.

\section{MATERIALS AND METHODS}

New colonies of $T$. biroi in traditional hives of coconut shell were set-up at lowland and upland ecosystems of Pili and Naga City, Camarines Sur. The lowland site is an urban areas located along the national highway at CBSUA, San Jose, Pili, Camarines Sur, (13 34' 59” N; $123^{\circ} 15^{\prime} 41^{\prime \prime}$ E) and Del Rosario, Naga City, Camarines Sur (13 ${ }^{\circ} 37^{\prime}$ $\left.8.9^{\prime \prime} \mathrm{N} ; 123^{\circ} 14^{\prime} 28.7^{\prime \prime} \mathrm{E}\right)$. The upland site is located at Mount Isarog Natural Park (MINP) at Curry, Pili, Camarines Sur (13 37' 19.3" N, 123 14' 29.4” E, $278 \mathrm{mASL}$ ), and Panicuason, Naga City (13 ${ }^{\circ} 39^{\prime}$ 54.7" N; 123 19' 46.0" E, 297 mASL). An elevation above 100 masl, with slightly sloping to rolling topography and a slope of equal or greater than $18 \%$ was considered an upland ecosystem, while in the lowland ecosystem the elevation is below 100 masl, the topography is flat or almost level (Asia Forest Network, 2007). The climatic condition in Camarines Sur is generally humid and hot particularly during the dry season months (February to May). Months of June to January is the wet season with September and October the wettest, while February and April are the driest. The average temperature is between 26.5 to $27.0^{\circ} \mathrm{C}$. The presence of flowering plants in the study sites was the primary consideration for setting up the colonies.

\section{Flowering Phenology}

Availability of floral resources in the four selected sites was determined within the 300-meter phenology transect that crisscrossed through the bees' colonies. Flowering plants that fall within the $300 \mathrm{~m}$ radius were identified and monitored whether the bees visited those plants. Only those plants observed to be visited by the bees were recorded and their bloom period was determined. For large trees, binocular was used to confirm the presence of the flowers.

\section{Pollen Sampling}

Pollen samples were collected from the pollen pots and the curbiculae of the returning foragers. Returning pollen foragers were captured at the hive entrances using a sweep net at three different time periods: 1) morning (between 7:00 a.m. and 10:30 a.m); 2) mid day (between 10:30 a.m. and 2:30 p.m.); 3) afternoon (between 2:30 p.m. and 5:00 p.m.) and the pollens were collected from the bees' hind legs, and stored in the refrigerator. Pollen load sampling was carried out in the lowland ecosystem due to the survival, growth and reproduction of the colonies. Likewise, samples of pollen were collected from the newly formed pollen pots every two months both in the lowland and upland ecosystems. These pollen pot samples were obtained from the previously placed halve coconut shells that served as the bees' new 
hives so as to avoid obtaining samples from the old stored pollen.

\section{Acetolysis}

Pollen treatment and analysis was performed at the Laboratory Facility of the Research Division at Central Bicol State University of Agriculture following the method of Erdtman, (1952) modified by Darmouth College Electron Microscope Facility.

Individual pollen samples were placed in $10 \mathrm{ml}$ centrifuge tubes and rehydrated by adding distilled water, $2 / 3$ of the volume of the tube followed by centrifugation for 5 minutes at $500 \mathrm{rpm}$. The water was decanted and $5 \mathrm{ml}$ of glacial acetic acid was added for washing the samples. Recentrifugation was done and the glacial acetic acid was decanted. Two $\mathrm{ml}$ of acetolysis fluid was added to the pollen samples, stirred and then placed in a boiling water bath for 10 minutes. The pollen samples were cooled down after andrecentrifuged at $500 \mathrm{rpm}$ for 5 minutes and acetolysis fluid was decanted. Samples was again washed in $5 \mathrm{ml}$ glacial acetic acid, centrifuged and decanted. Pollen was rehydrated with two to three washes of distilled water each followed by centrifugation. After washing, glycerin was added twice the volume of the samples, stirred with a spatula and was kept for pollen identification and analysis.

\section{Characterization and Identification of Pollen}

This procedure determines the pollen types present in the samples. Pollen types refer to the plant species producing such type of pollen and the basis was on certain pollen grain character and not the taxonomical identity of the plant. To facilitate identification of pollen types, the method by De Klerk and Joosten (2007) wasadopted. There is no coherent and widely accepted pollen nomenclature.

Identification and morphological characterization of pollen were facilitated by light microscopy using the binocular compound microscope. Some technical monographs, books and other reference materials such as of Kiew and Muid (1991); Roubik and Patino (2003) were consulted to facilitate identification. Fresh pollens were also collected from the flowers, acetolyzed and examined under the microscope and were compared with the pollens collected.
Photomicrographs of representative pollen types were taken.

\section{Quantitative Pollen Analysis}

The quantitative pollen analysis determined the pollen spectrum which gives the relative proportion and the importance of the different pollen types. This was done by counting 300 pollen grains per sample using hemocytometer. Percentage occurrence of pollen and its corresponding value to the stingless bees were derived from Louveaux, et al (1978) as follows:

Predominant Pollen (Dp)- represented by more than $45 \%$ of the total pollen grains counted

Secondary Pollen(Sp)-16 to $45 \%$ of the total pollen grains counted

Important minor pollen(Ip)-3 to $15 \%$ of the total pollen grains counted

Minor pollen (Mp)-less than $3 \%$ of the total pollen grains counted.

\section{Statistical Analysis}

Regression Analysis was used in the computation of data using the Wessa, Free Statistics Software Version 1.1.23-r6, URL http://www.wessa.net .

Rarefaction analysis was used for the computation of monthly percentage occurrence of pollens. Species richness (pollen richness) was used to estimate pollen diversity using the EstimateS Software version 7.5. Persistent URL <purl.oclc.org/estimates>.

Rarefaction techniques are used to quantify species diversity of newly studied ecosystems and for such reason, the technique was applied in this study. Estimating pollen diversity in the two lowland sites is new since no studies have been made on such ecosystem. Rarefaction analysis and pollen richness were computed in the lowland ecosystem to further verify its suitability to meliponiculture.

\section{RESULTS}

Tetragonula biroi visited 121 plant species representing 100 genera and 49 families across four sites. Herbs predominate among the plants visited by the stingless bees (35\%), followed by trees $(31 \%)$, shrubs (20\%), palms (7\%) and vines (7\%). A total of 111 plant species visited in the lowland ecosystem 
and only 42 species in the upland ecosystem. Leguminosae and Asteraceae were the highest in terms of genera and plant species visited in the lowland and upland ecosystem. Palmae, Myrtaceae, Rubiaceae, Malvaceae, Rutaceae, Lythraceae, Apocynaceae, Cyperaceae, Cucurbitaceae, Graminae, Musaceae, Oxalidaceae and Sapotaceae have more than two species visited by stingless bees.

\section{Density of Plants and Bloom Pattern}

The majority of the plants $(53 \%)$ blooms throughout the year, $35 \%$ were seasonal, and $15 \%$ with intermittent flowering behavior. The months of January to May had the highest number of plants in bloom which peak in March with 75\%. The secondary flowering period was observed from July to August with 64\% - 69\%; and low number of flowering from October to December with only $58 \%$. The monthly density of species that bloom differed in both ecosystems due to the species variation. At the lowland ecosystem, the higher density was recorded at CBSUA than at Del Rosario.

In Camarines Sur, the flowering season begins in January coinciding with the intense flowering of some important fruit trees such as Mangifera indica, Persia americana, Averrhoa bilimbi, Ceiba pentandra, palms and shade trees. A succession of the flowering was observed from January until May and becomes intense from February to May. This flowering season is the called honey flow season by beekeepers in the Philippines indicating that one or more major nectar sources are in bloom and the weather is encouraging for the bees to fly and collect nectar and pollen in large quantities. For $T$. biro $i$ more honey pots and pollen pots are formed by the bees during these months. In contrast, the dearth period follows after the main flowering season commencing from June to December coinciding with the wet season. This period was unfavorable for the stingless bees since they relied solely on the natural sources of pollens and nectar from their surroundings. Aside from limited food resources, rainfall prevented the bees to forage. Dearth period adversely affected the colonies of stingless bees' set-up in the upland ecosystem particularly during the last six months of establishment. There was no or very little pollen was brought to the hive and likewise none or very few new pollen pots and honey pots formed. The coconut shells placed in the colony to serve as the new hive of the bees were empty indicating that the bees have not gathered enough food. The frequent rains, low temperature and strong breeze weaken the bees and death of some of the colonies was observed. According to Chandrasekaran, et al, (2010) in the upland, temperature decreases by $1.8^{\circ} \mathrm{C}$ for every 300 meters above sea level. The stingless bee's colonies were set up to nearly $300 \mathrm{~m} \mathrm{ASL}$ and the temperature was observed to be almost 2 degrees lowered than the lowland ecosystems. These conditions (low temperature and rainfall) hindered the foraging activities of the stingless bees, prevented them from flying outside the hive to search for food. Bloom pattern, therefore, is very important as this determined the honey flow season and the dearth period of the bees.

\section{Pollen Spectrum}

T. biroi collected pollens from 43 families and 84 plant species or $69.4 \%$ of the total number of plants visited by stingless bees across all sites. A total of 61 pollen types were identified at the CBSUA with 59 in the pollen loads and 54 in the pollen pots. The pollen types identified at CBSUA represents $49 \%$ of the total plants visited by stingless bees across all sites. In Del Rosario, 47 pollen types found in the pollen loads and 39 in the pollen pots which represents $39 \%$ of the total number of identified plants in all sites. However, several pollen types were found in the pollen pots but not found in the pollen loads such as A. bilimbi, A. carambola, Samaneasaman, Veronica peregrine and Zea mays. Likewise, Cyperus kyllingia, Ipomea triloba, Lagerstroemia speciosa, Momordica charantia, Tecomastans, and Manilkarazapota were found in the pollen loads. For the upland ecosystem, 33 pollen types identified at Curry while Panicuason had 22 with 3 unidentified pollen types. Pollens of 37 plants visited by the stingless bees were not observed in the collected pollen samples. These plants either produced very little pollen, or very few were gathered by the bees, thus, these were under-represented in the collected samples.

Eighty-four percent of the pollen types were minor pollens (Mp) and important minor pollens (Ip).

Their occurrence in the samples was $0.33 \%$ to $2.9 \%$. These pollens were occasionally or rarely collected 
by stingless bees. Though their occurrence was very small, it was found out that during the rainy season and dearth period, these pollens sustain the food requirements of the bees.

Only $16 \%$ of the pollens collected were secondary to predominant pollens. These pollens were the major pollen sources of the stingless bees because of their higher percentage occurrence in the samples. It means that bees regularly visited those plants to collect pollens. The predominant pollen types such as Cocos nucifera, Ceiba pentandra, Syzygium samarangensi, Pterocarpus indicus, Elaeis guineensis and Mangifera indica accounted for $7 \%$ of all the pollen types. Although most of these plants were nonseasonal, bees collected enormous amounts of pollens during their bloom period.
Pollens from Asteraceae, Leguminosae, Palmae, Myrtaceae, Cyperaceae, Graminae, Musaceae, Cucurbitaceae and Balsaminaceae were present in the pollen samples collected from all sites. Cocos nucifera pollens were present in all sites which constituted $19-24 \%$ of the pollens from May to November and $47-73 \%$ from June to October. Likewise, pollens of the following plant species, namely; Ceiba pentandra, Mangifera indica, Elaeis guineensis ,Pterocarpus indicus, Syzygium spp., Persia americana, Areca catechu and Citrus spp. were dominant to secondary pollen sources in the lowland ecosystem. On the other hand, Citrus spp. and Muntingia calabura were the dominant pollen sources in the upland ecosystem. The lists of some pollen types, their forage value and bloom period is shown in Table 1.

Table 1.Pollen types, forage value and flowering period of T. biroi plants in lowland and upland ecosystems of Pili, and Naga City, Camarines Sur. Notes: Dp= predominant pollen (> 45\%); Sp = secondary pollen $(15 \%-$ $45 \%) ;$ Ip= important minor pollen $(3 \%-15 \%) ; M p=$ minor pollen $(<3 \%)$.

\begin{tabular}{|c|c|c|c|c|}
\hline Pollen Types & Family & Habit & Forage Value & Flowering Period \\
\hline Areca catechu & Arecaceae & tree & Sp-Dp & July-August \\
\hline Artemisia vulgaris & Asteraceae & herb & $\mathrm{Mp}$ & February -May \\
\hline Artocarpusheterophyllus & Moraceae & tree & $\mathrm{Mp}-\mathrm{Sp}$ & All year round \\
\hline Averrhoabilimbi & Oxalidaceae & tree & Mp-Ip & April-May \\
\hline Bidenspilosa & Asteraceae & herb & Mp-Ip & All year round \\
\hline Canariumovatum & Burseraceae & tree & $\mathrm{Mp}-\mathrm{Sp}$ & February-May \\
\hline Ceibapentandra & Bombaceae & tree & Sp-Dp & December-January \\
\hline Citrus spp. & Rutaceae & shrub & $\mathrm{Mp}-\mathrm{Sp}$ & Feb- September \\
\hline Cleome rutidesperma & Capparidaceae & herb & Mp-Ip & All year round \\
\hline Cocosnucifera & Arecaceae & tree & Sp-Dp & All year round \\
\hline Delonixregia & Leguminosae & tree & Ip & May-July \\
\hline Elaeisguineensis & Arecaceae & tree & $\mathrm{Mp}-\mathrm{Sp}$ & January-April \\
\hline Gliciridiasepium & Leguminosae & tree & Mp-Ip & February-April \\
\hline Impatiens balsamina & Balsaminaceae & herb & Mp-Ip & All year round \\
\hline Jatrophaintegerrima & Euphorbiaceae & shrub & $\mathrm{Mp}$ & All year round \\
\hline Mangiferaindica & Anacardiaceae & tree & Mp-Sp & December-March \\
\hline Muntingiacalabura & Tiliaceae & tree & Sp-Dp & All year round \\
\hline Persia americana & Laureaceae & tree & Ip & February-March \\
\hline Pterocarpusindicus & Leguminosae & tree & $\mathrm{Dp}$ & February-March \\
\hline Solidagovirgaurea & Asteraceae & herb & Mp-Ip & all year round \\
\hline Syzygium spp. & Myrtaceae & tree & Mp-Dp & April-June \\
\hline Talinumtriangulare & Portulaceae & herb & Mp-Ip & All year round \\
\hline Veitchiamerrillii & Arecaceae & tree & $\mathrm{Mp}-\mathrm{Sp}$ & All year round \\
\hline
\end{tabular}


Relationship of Bloom Pattern to the Diversity of Foraged Pollens

The diversity of pollens collected by stingless bees showed a linear relationship with the bloom pattern. Interpolation of foraged pollens and flowering plants plotted against time showed that both pollen diversity and abundance of blooming plants increased during the 12- month study period in the lowland ecosystem as shown in Figures $1 \& 2$.However, results indicated that the diversity of the monthly foraged pollen and was not affected by the monthly bloom pattern.

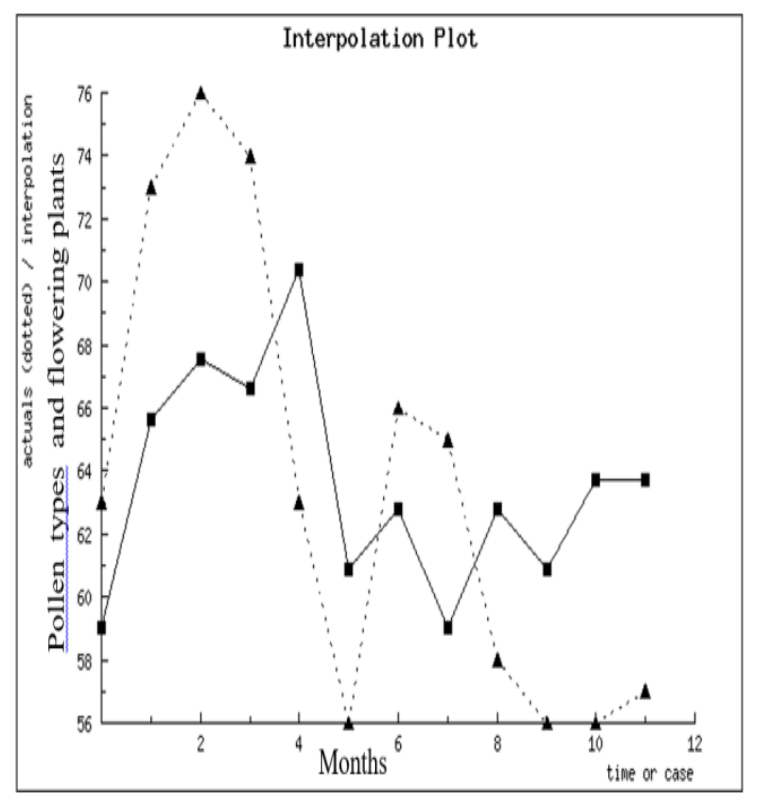

Figure 1.Interpolation of pollen types and flowering plants plotted against time at San Jose, Pili, Camarines Sur. $\mathbf{\square}$-flowering plants $\boldsymbol{\Delta}$-pollen types

Pollen richness was higher in San Jose during the first part of the year (January to May) than the later part except in September which had the highest species richness and the greatest variability $(95 \%$ confidence limits of 28.88 to 95.36 ). Species richness was lowest in August and October. The lower 95\% confidence limits for the 12 months sampling overlaps and were generally below the computed mean richness, except in November (Table 2). The species richness in Del Rosario started to rise from February to April reaching its peak in May, followed by a drastic reduction in June (Table 3 ).

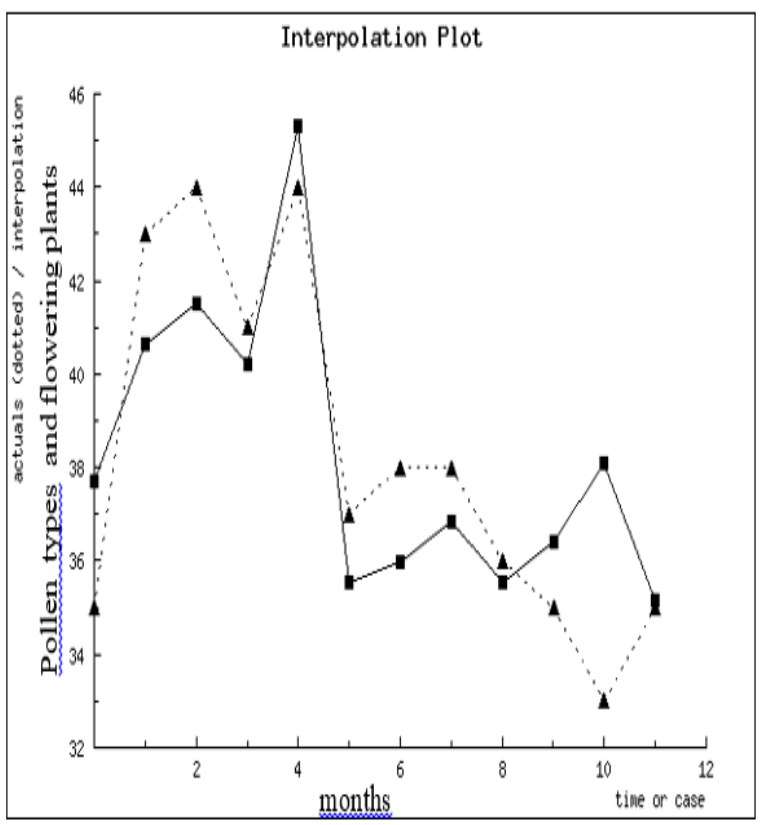

Figure 2. Interpolation of pollen types and flowering plants plotted against time at Del Rosario, Naga City, Camarines Sur -flowering plants $\boldsymbol{\Delta}$-pollen types

The months with overlapping confidence intervals were observed in February, March, and April which mean that these months have similar pollen richness. Regressing pollen richness with bloom pattern did not show significant differences in the lowland ecosystem. Likewise, analysis of the F-values obtained in both sites showed non-significant differences at $1 \%$ and $5 \%$ level. 
Proceedings of the $3^{\text {rd }}$ International Conference on Agriculture and Forestry, Vol. 2, 2016, pp. 116-126

Table 2. Monthly species richness at San Jose based on Chao estimate. Notes: *Chao= Chao 2 richness estimator (mean among 6 runs), log-linear confidence interval lower and upper bounds. Months with overlapping confidence intervals, having common letters, are not significantly different at $5 \%$ level.

\begin{tabular}{ccccc}
\hline Months & Mean *(Chao2) & $\frac{95 \% \text { Confidence }}{\text { Lower }}$ & $\begin{array}{l}\text { Limits } \\
\text { Upper }\end{array}$ & Difference \\
\hline January & 22.67 & 21.26 & 31.57 & $\mathrm{ab}$ \\
\hline February & 33.18 & 32.27 & 40.98 & $\mathrm{a}$ \\
\hline March & 29.79 & 29.09 & 34.24 & $\mathrm{a}$ \\
\hline April & 30.00 & 27.67 & 40.37 & $\mathrm{a}$ \\
\hline May & 33.56 & 32.27 & 40.98 & $\mathrm{a}$ \\
\hline June & 33.67 & 22.24 & 33.54 & $\mathrm{ab}$ \\
\hline July & 26.80 & 24.53 & 38.78 & $\mathrm{ab}$ \\
\hline August & 20.33 & 20.07 & 24.67 & $\mathrm{~b}$ \\
\hline September & 42.67 & 28.88 & 95.36 & $\mathrm{a}$ \\
\hline October & 22.40 & 23.03 & 27.27 & $\mathrm{~b}$ \\
\hline November & 26.00 & 26.00 & 30.08 & $\mathrm{ab}$ \\
\hline December & 27.00 & 25.33 & 37.15 & $\mathrm{ab}$ \\
\hline
\end{tabular}


Table 3. Monthly species richness at Del Rosario, Naga City based on Chao estimate. Notes: *Chao2

= Chao 2 richness estimator (mean among 6 runs), log-linear confidenceinterval lower and upper bounds. Months with overlapping confidence intervals, have common letters, are not significantly different at $5 \%$ level.

\begin{tabular}{ccccc}
\hline Months & Mean *(Chao2) & $\begin{array}{c}\text { 95\% Confidence } \\
\text { Lower }\end{array}$ & $\begin{array}{c}\text { Limits } \\
\text { Upper }\end{array}$ & \multirow{2}{*}{ Difference } \\
\hline January & 13.00 & 13.00 & 15.70 & $\mathrm{C}$ \\
\hline February & 20.36 & 20.03 & 24.46 & $\mathrm{~B}$ \\
\hline March & 21.95 & 21.12 & 28.63 & $\mathrm{~B}$ \\
\hline April & 20.33 & 19.18 & 28.72 & $\mathrm{~B}$ \\
\hline May & 31.00 & 31.00 & 37.11 & $\mathrm{~A}$ \\
\hline June & 5.22 & 5.01 & 9.38 & $\mathrm{E}$ \\
\hline July & 9.67 & 9.05 & 18.33 & $\mathrm{Cd}$ \\
\hline August & 11.5 & 11.04 & 17.14 & $\mathrm{Cd}$ \\
\hline September & 8.00 & 8.00 & 10.37 & $\mathrm{De}$ \\
\hline October & 10.00 & 10.00 & 12.56 & $\mathrm{D}$ \\
\hline November & 14.00 & 14.00 & 16.66 & $\mathrm{C}$ \\
\hline December & 7.00 & 7.00 & 9.07 & $\mathrm{E}$ \\
\hline
\end{tabular}

\section{DISCUSSION}

More than one hundred plant taxa were visited by $T$. biroiin four selected sites. The majority of the plants visited by the bees were cultivated species and common in the province. As such, their availability is not a problem as these can be grown easily and establish in the potential beekeeping sites.

No difference in the blooming period noted between lowland and upland ecosystems. The observed similarity in the blooming pattern was probably because of little distinction in the climatic condition. Both ecosystems showed a peak of flowering from February to May which coincided with the dry season. As such, it is the honey flow season or pollen season of the stingless bees with nectar and pollen sources abundant and readily available. The difference in the density of the species that flowered every month between the two ecosystems may be influenced by the kinds of flowering plants growing in such areas affected by topography or slope, seasonality of the species and the change in the cropping system because of the change in season.

The bloom period clearly affected the foraging activity of the stingless bees. Stingless bees showed a very active foraging in the dry season when the majority of the flowers bloom. The effective foraging distance is likely between 50-150 meters depending upon the floral resources available and probably the level of disturbances in the area where colonies are located. Stingless bees did not show special preference to the morphology of a flower as various flower types, colors, sizes and scents were collected with pollens (Figure 3). Stingless bees having a minute body of $3-5 \mathrm{~mm}$ is an advantage because it could forage and /or enter the corolla of the medium to large flowers and explore efficiently for nectar or pollens.

Palms which are abundant in the province are very important pollen sources of T.biroi. Palms forage value to $T$. biroiare minor to dominant pollen sources. The coconut was the major pollen source as their pollens were present in all the samples collected from 


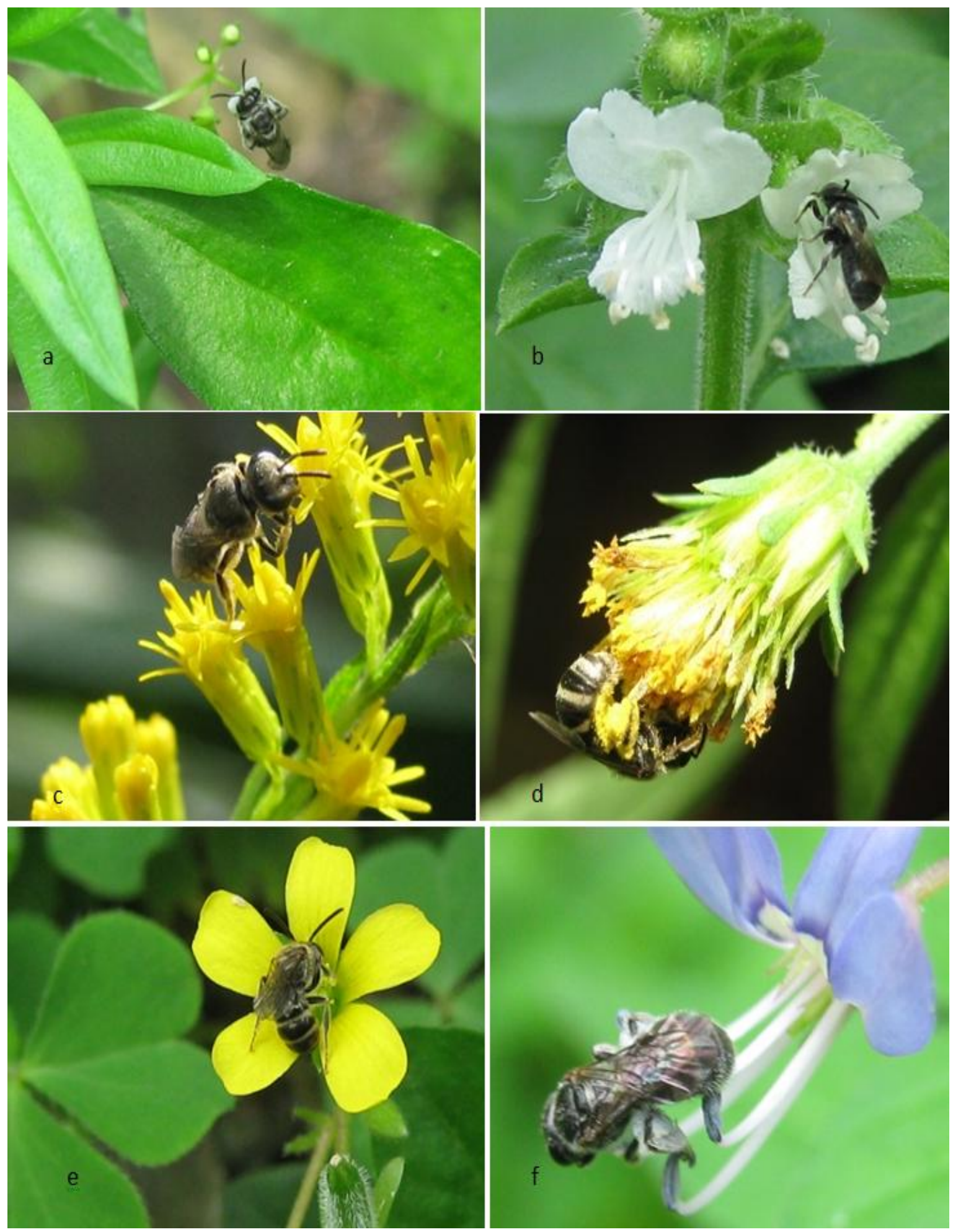

Figure 3. Cultivated and feral pollen sources of T. biroi having tiny and small flowers (a) Veronica peregrina(b) Ocimumbasilicum(c)Solidagovirgaurea (d)Bidenspilosa(e) Oxalis sp. (f) Cleome rutidesperma. 
all sites, and were always encountered during monthly sampling. Major pollen sources during the short blooming period include Ceibapentandra, Ptercarpusindicus, Syzigium spp., Elaeisguineensis, Areca catechu, Citrus spp. and Delonixregia.

These plants were also considered secondary to dominant pollen sources during certain months of the year including other species of Leguminosae, Asteraceae, Myrtaceae, and Rutaceae families.

Pollen spectrum is dependent on the kinds and number of flowering plants available in the vicinity of the colonies with a minor consideration on the preferences of the stingless bees. The abundance of flowering plants preferred by stingless bees influenced the diversity of the foraged pollens.

Rarefaction curve and pollen richness in the lowland ecosystem was higher in May than the rest of the months. Marked differences in species richness were noted in June and September. The higher 95\% confidence limits from February to May signifies that stingless bees frequently visited flowering plants and collected higher amounts of pollens. The overlapping of the lower $95 \%$ confidence limits during the 12 months sampling showed that the pollens gathered have a common foraged value to the stingless bees.

\section{CONCLUSION}

The analysis of stingless bee pollens enhanced our knowledge of the T. biroi botany. Majority of the plants visited by the bees were cultivated species. As such, their availability is not a problem as these can be grown easily and establish in the potential beekeeping sites. Knowledge of the major flowering period is the ideal time to divide the colonies because of the abundance of their food sources. Moreover, the palynological composition of the pollen loads and the pollen pots described the local flora surrounding the beehive and this provides an indication of the biodiversity of the area.The results of this study guidethe beekeepers in determining areas suitable for meliponiculture.

\section{REFERENCES}

Buchmann, S.T. and Nabhan, G.P.. 1996. The forgotten pollinators. Washington, D.C. Inland Press.

Chao, Anne. 1984. Non-parametric estimation of the number of classes in a Population. Scandinavian
Journal of Statistics 11:265-270 http://viceroy.eeb.uconn.edu/estimatespages/EstSUse rsGuide/References/Chao1984.pdf

Chao, A. 2004. Species richness estimation. In: N. Balakrishnan, C.B. Read and B. Vidaovick eds. Encyclopedia of Statistical Sciences. Wiley, New York. In press.

Colwell, R. K., Mao, C.X. and .Chang, J. 2004. Interpolating, extrapolating and comparing incidencebased species accumulation curves. Ecology 85:27172721.

De Klerk, Pin and Joosten, Hans. 2007. The difference between pollen types and plant taxa for clarity and scientific freedom. Eiszetalter und Gegenwart/Quartenary Science Journal 56: 162-171.

Eltz,T.,Bruhl,C.A., Van Der Kaars, S., Chey, V.K. and Linsenmair K.E.. 2001. Pollen foraging and resource partitioning of stingless bees in relation to flowering dynamics in a Southeast Asian tropical rainforest. InsectesSociaux 48(2001)273-279.

Erdtman, G. 1952. Pollen morphology and plant taxonomy-Angiosperms. Stockholm: Almquist and Wiksell.

Grogan, D. E., and J. Hunt,J.H. 1979. Pollen proteases: their potential role in insect digestion. Insect Biochem. 9:309-313.

Jongjitvimol,T. and Wattanachaiyingcharoen, W. . 2006. Pollen food sources of the stingless bees Trigonaapicalis Smith,1857, Trigonacollina Smith, 1857 and Trigonafimbriata Smith, 1857 (Apidae,Meliponinae)in Thailand. The Natural History Journal of Chulalongkorn University 6(2):75-82..

Kevan, P.G. 1995. Bee botany: Pollination, foraging and floral calendars. In: The Asiatic Bee Hive:Apiculture, Biology and Role in Sustainable Development in Tropical and Subtropical Asia. Peter K. Kevan, ed. Enviroquest Ltd. Cambridge, Ontario, Canada, pp. 113-116.

Kiew, Ruth and Muid, Muhammad. 1991. Beekeeping in Malaysia: Pollen Atlas Malaysian Beekeeping Research and Development Team. United Selangor Press SdnBhd Kuala Lumpur, Malaysia p186.

Mostoles, M.D.J. and Ruiz,R.B. 2004. The Bicolanoexperience. In: Bees for Asia. Proceedings of the Asian Apiculture Association Conference, 2327 February, 2004. pp.295-300.

Mostoles, M.D.J., Ruiz, R.B., Balderas, M. B., Nicolas,A.R., Del Rosario, A. and Abad, A.. 2006. Inventory of native bees in Bicol. Paper presented in the 18th Regional Research Highlights, BICARRD, Pili, Camarines Sur.

Philippine Council For Agriculture, Forestry And Natural Resources Research And Development, 
(Pcafnrrd). 2007. Bee inventory in the Bicol Region (Philippines) Los Banos, Laguna (Philippines)-Dept. of Science and Technology.

http://agris.fao.org/aos/records/PH2009000054

Roubik, D.W. 1989. Ecology and natural history of tropical bees, Cambridge University Press, Cambridge.

Ruiz, R. B., .Mostoles, M.D.J. and Palconitin, R.O. 2003. Cultural management

practices of the stingless bee in Bicol. The CSSAC Journal of Research VI.(1):1-7.
WESSA, P. 2011. Free Statistics Software, Office for Research Development and Education, version 1.123r6, URL http://www.wessa.net

Wilms W., Imperatriz-Fonseca, V.L., Engels, W. 1996. Resource partitioning between highly eusocial bees and possible impact of the introduced Africanized honey bee on native stingless bees in the Brazilian Atlantic rainforest, Stud. Neotrop. Fauna Environ. 31, 137-151.

2007. Upland Philippine Communities: Guardians Of The Final Forest Frontiers.

http://www.asiaforestnetwork.org/pub/pub07.html 